\title{
Perhitungan Energi Bagi Kebutuhan Pengepresan Kopra Pada Perancangan Mesin Press Minyak Kelapa
}

\author{
${ }^{1}$ Richard A. M. Napitupulu, ${ }^{1}$ Alberto Hutauruk, ${ }^{1}$ Miduk Tampubolon, ${ }^{2}$ Lestina Siagian, \\ ${ }^{1}$ Parulian Siagian \\ Program Studi Teknik Mesin, Universitas HKBP Nommensen, Medan 20234 \\ Program Studi Teknik Elektro, Universitas HKBP Nommensen, Medan 20234 \\ richard_alf@yahoo.com
}

\begin{abstract}
An experiment has been conducted to determine the amount of deformation energy and energy per volume needed for the design of coconut oil press machines. By using a press tube with a diameter of $59 \mathrm{~mm}$ and by varying the load of press and speed of press the results obtained that to produce the optimal average volume of coconut oil are at the pressure load of $40 \mathrm{KN}$ and the pressure rate of $6 \mathrm{~mm} /$ minute. The ideal energy per volume used to suppress coconut oil press machine is $6.10^{6} \mathrm{~J} / \mathrm{m}^{3}$.
\end{abstract}

Keywords : energy, coconut oil, press machine

\section{PENDAHULUAN}

Kelapa merupakan tanaman perkebunan atau industri dengan batang tanaman yang tinggi. Pada dasarnya dua varietas kelapa, yaitu variates mana yang umum disebut kelapa genjah, dan variates typica yang umumnya disebut kelapa dalam. Tanaman kelapa yang juga disebut pohon kehidupan, merupakan tanaman serba guna, karena disetiap bagian tanaman dapat diambil hasilnya untuk memenuhi sebagian kebutuhan hidup manusia. Kelapa merupakan tanaman tropis yang penting bagi negara-negara Asia dan Pasifik. Kelapa selain dapat memberikan devisa bagi Negara juga merupakan mata pencarian jutaan petani, yang mampu memberikan penghidupan puluhan juta keluarganya. Dan menurut FAO (Food and Agriculture Organization) pada tahun 1976, negara-negara di Asia dan Pasifik menghasilkan 82\% dari produksi kelapa dunia, sedangkan sisanya dihasilkan oleh negara Afrika dan Amerika Selatan [1].

Minyak kelapa merupakan bagian paling berharga dari buah kelapa. Kandungan minyak pada daging buah kelapa tua adalah sekitarannya 34,7\%. Minyak kelapa digunakan sebagai bahan baku industri, atau sebagai minyak goreng. Minyak kelapa dapat diekstrak dari daging kelapa segar, atau diekstrak dari daging kelapa yang telah dikeringkan (kopra)[2].

Sebelum era decade 80-an, minyak kelapa banyak digunakan sebagai minyak untuk memasak / menggoreng bahan makanan. Hanya saja seiring dengan perkembangan perusahaan kelapa sawit, minyak kelapa ini mulai jarang ditemukan, padahal untuk kesehatan minyak kelapa jauh lebih baik dari minyak kelapa sawit. Untuk mengembalikan kembali pemakaian minyak kelapa kepada masyarakat, maka perlu diproduksi kembali baik dalam skala kecil maupun besar. Beberapa penelitian telah dilakukan untuk memperoleh kualitas kopra yang baik sebagai sumber bahan baku minyak kelapa seperti yang dilakukan oleh Thiruchelvam Thanaraj (2007) yang mencoba menghitung kualitas kopra dengan pengeringan sinar matahari dan rumah kiln [3]. Begitu juga yang dilakukan M Mohanraj (2008) yang meningkatkan kualitas pengeringan kora dengan menggunakan bantuan cahaya matahari dengan metode konveksi paksa [4].

Untuk memproduksi minyak kelapa dapat dilakukan memakai metode basah dan metode kering dengan cara ditekan/dipres [5]. Pada metode basah, Sujeta dan H. Das (2007) mencoba memodelkan karakteristik dari santan kental hasil perasan dari kopra dengan menggunakan variasi temperature dan ketebalan lapisan santan pada tabung bertekanan [6]. Pembuatan 
minyak kelapa dengan cara kering yaitu dengan mengeringkan daging buah kelapa melalui pemanasan minimum kemudian melakukan pengepresan secara mekanik terhadap buah kering. Untuk metode kering dengan cara ditekan/dipres masih perlu didesain mesin tekan/press kelapa. Agar mesin press yang didesain nantinya cukup produktif dan efisien, maka perlu terlebih dahulu diketahui berapa besar energi yang dibutuhkan untuk mengepress kopra menjadi minyak kelapa.

Energi deformasi yang terjadi selama proses penekanan dengan menggunakan universal testing machine dapat diketahui dengan menghitung luas kurva gaya tekan dan elongasi yang terjadi akibat penekanan suatu bahan [7,8], dan menurut A. Kabutey dan kawan-kawan (2014), besar energi yang dibutuhkan dapat dihitung dengan rumus [9]

$$
E=\sum_{n=0}^{n=I-1}\left[\left(\frac{F_{n+1}+F_{n}}{2}\right) \times\left(x_{n+1}-x_{n}\right)\right]
$$

dimana :

E - deformation energy (J)

$F_{n}, F_{n+1}-$ values of compressive force (N)

$X_{n}, X_{n+1}$ - values of seed deformation (m)

Sementara itu volume penekanan kopra dapat dihitung dengan rumus :

$$
V=\frac{\pi \times D^{2}}{4} \times H
$$

dimana : $\quad \mathrm{V}=$ volume kopra yang ditekan

$\mathrm{D}=$ diameter tabung press $=59 \mathrm{~mm}$

$\mathrm{H}=$ ketinggian kopra pada tabung press yaitu $60 \mathrm{~mm}$ untuk setiap penekanan.

Sehingga besar energi per unit volume, yang juga dikenal dengan istilah ketangguhan adalah

$$
e=\frac{E}{V}
$$

dimana

$e$ - volume energy $\left(\mathrm{J} / \mathrm{m}^{3}\right)$

$E$ - deformation energy ( $\mathrm{J})$

$V$ - pressing seed volume $\left(\mathrm{m}^{3}\right)$

\section{METODE PENELITIAN}

\subsection{Pengeringan Kopra}

Kelapa dibelah menjadi dua untuk membuang air kelapa. Kemudian kopra dipecah sehingga menjadi beberapa potongan kecil dan kopra dilepaskan dari kulit luar kelapa. Setelah kopra sudah lepas dari kulit kelapa, potongan-potongan kecil kopra tersebut diletakkan secara rapi pada setiap loyang secara bertingkat dan dimasukkan kedalam mesin pengering seperti gambar 1 . Kemudian dikeringkan di mesin pengering dengan suhu $68^{\circ} \mathrm{C}$ dan kecepatan udara $2.18 \mathrm{~m} /$ detik. Tukar susunan tingkat loyang pada mesin pengering setiap sejam sekali guna membuat kopra kering secara merata selama 12 jam non stop. Setelah itu kopra yang sudah kering dikukur dengan alat kukur sederhana. 


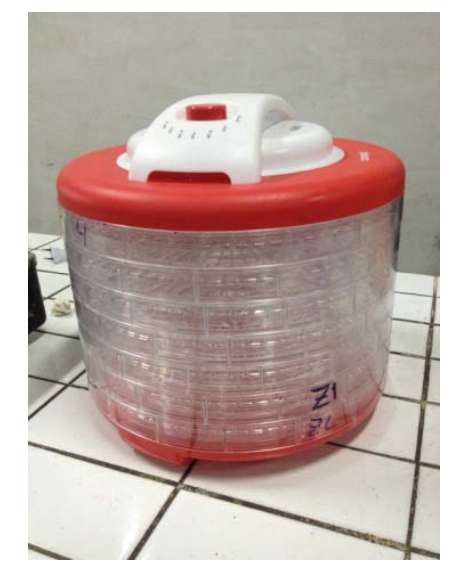

Gambar 1. Mesin Pengering

\subsection{Penekanan Kopra}

Kopra yang sudah dikukur terlebih dahulu ditimbang dengan menggunakan timbangan digital sebelum dimasukkan kedalam tabung alat pengepress seperti pada gambar 1 . Kemudian kopra yang terdapat dalam tabung pengepress ditekan menggunakan mesin uji tekan seperti gambar 2 dengan terlebih dahulu diatur kecepatan dan beban nya saat pengepressan. Setelah pengepressan selesai, ampas kopra dikeluarkan dari dalam tabung pengepress lalu ditimbang dengan timbangan digital untuk dicatat sebagai persentase mekanisnya.

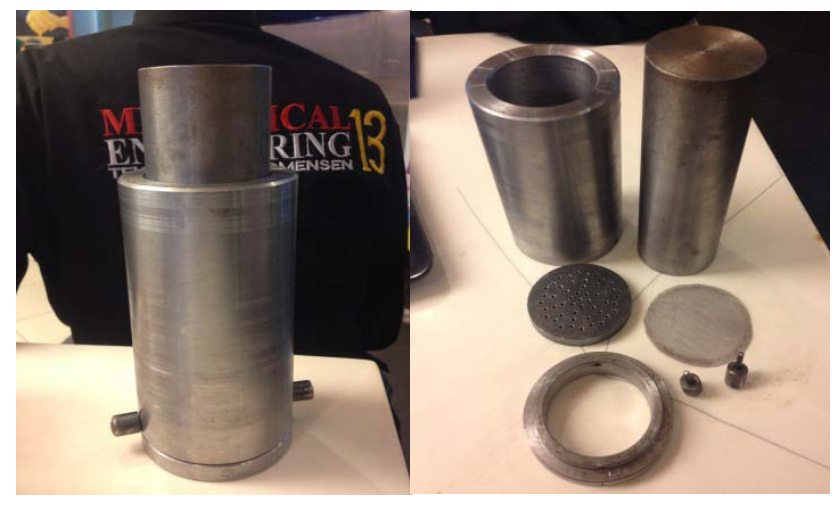

Gambar 2. Tabung Press 


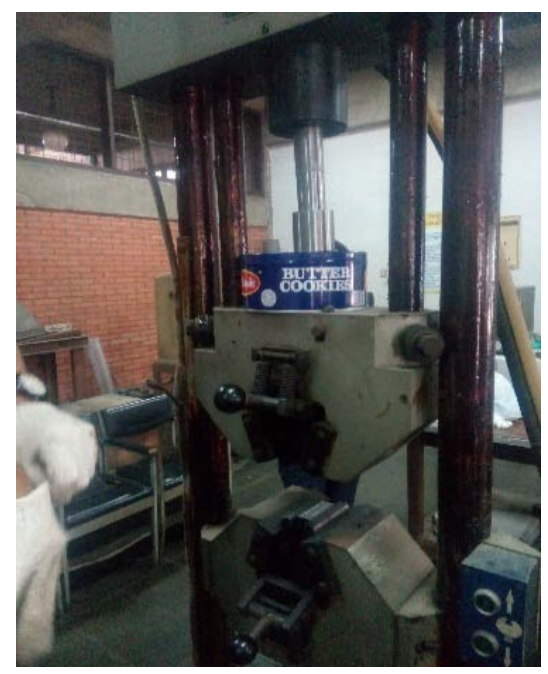

Gambar 3. Universal Testing Machine (Mesin Uji Tekan)

\section{HASIL DAN PEMBAHASAN}

\subsection{Hasil}

Dengan menvariasikan besar gaya dan kecepatan penekanan pada mesin uji tekan, diperoleh data-data hubungan antara besar gaya penekanan dan deformasi yang terjadi pada kecepatan penekanan tertentu seperti pada gambar dibawah ini.

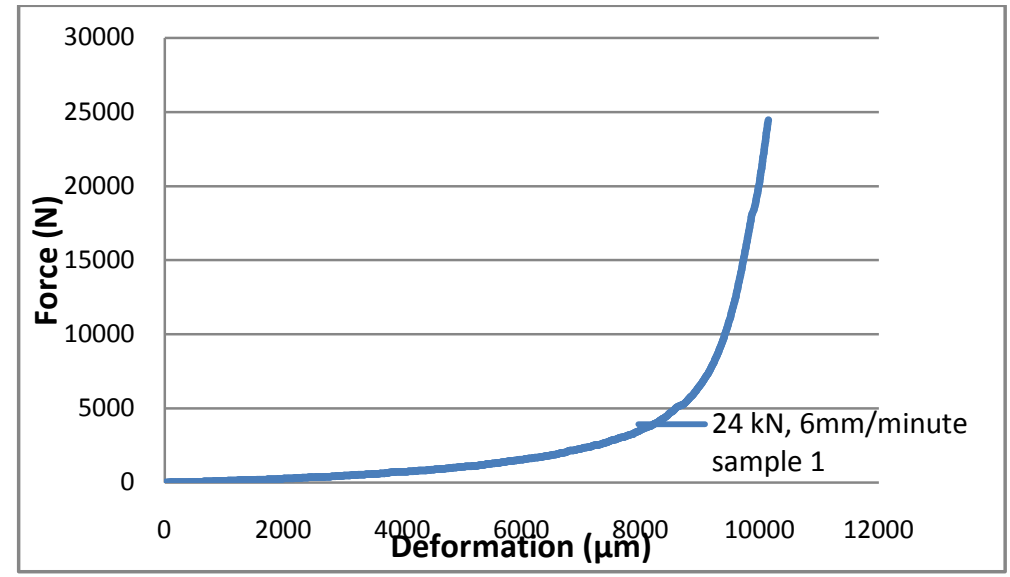

Gambar 4. Grafik hubungan Gaya dan Deformasi yang terjadi dengan beban tekan 24kN pada kecepatan $6 \mathrm{~mm} / \mathrm{menit}$ 


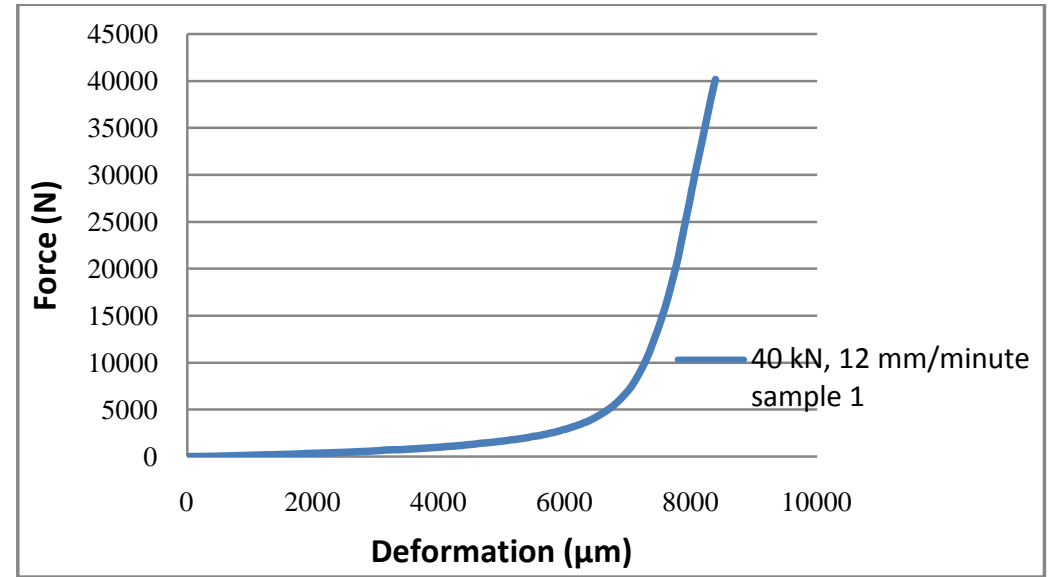

Gambar 5. Grafik hubungan Gaya dan Deformasi yang terjadi dengan beban tekan 40kN pada kecepatan $12 \mathrm{~mm} / \mathrm{menit}$

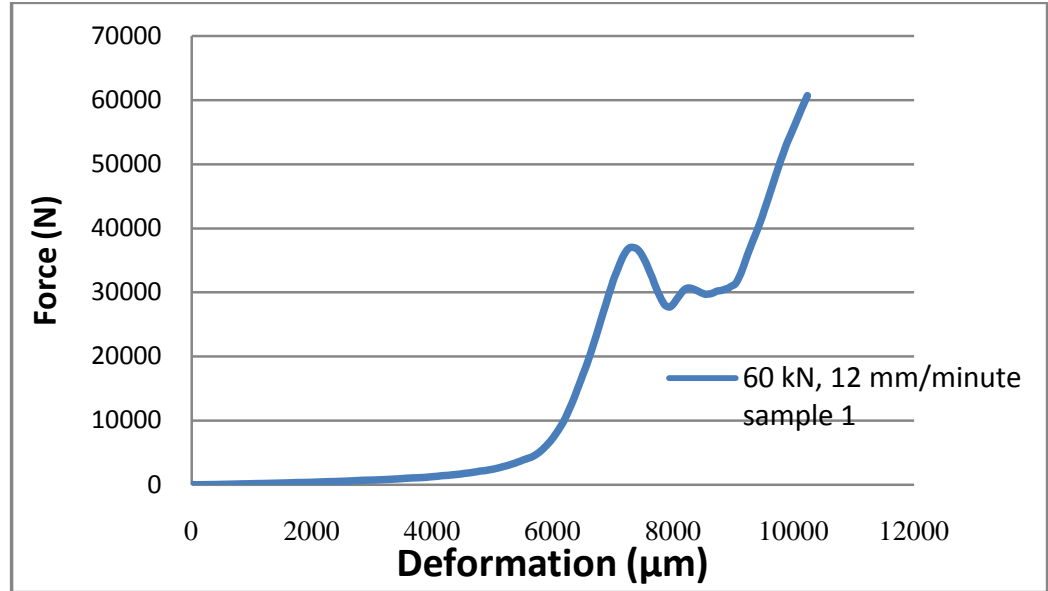

Gambar 6. Grafik hubungan Gaya dan Deformasi yang terjadi dengan beban tekan 60kN pada kecepatan $12 \mathrm{~mm} / \mathrm{menit}$

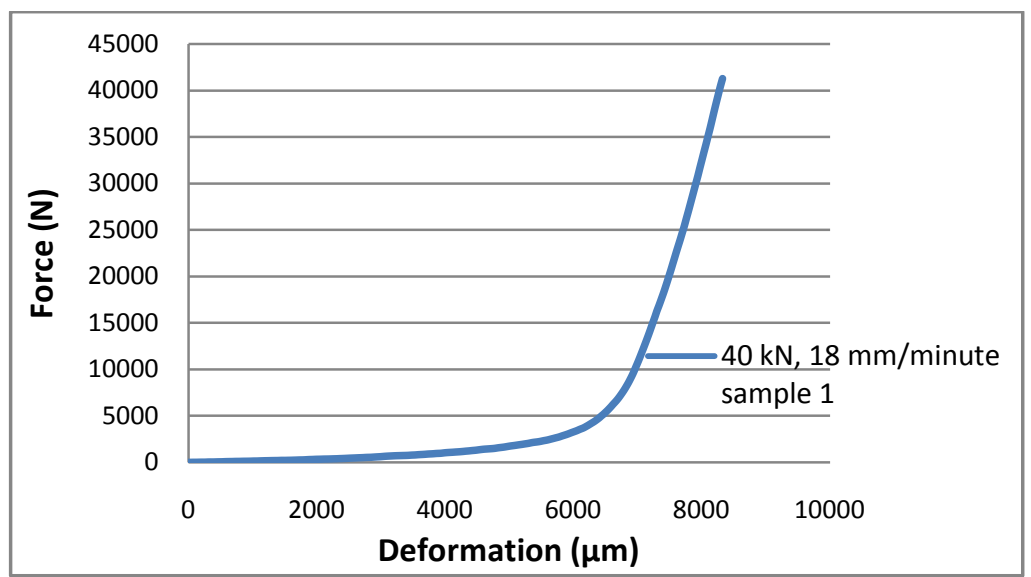

Gambar 7. Grafik hubungan Gaya dan Deformasi yang terjadi dengan beban tekan 40kN pada kecepatan $18 \mathrm{~mm} / \mathrm{menit}$ 


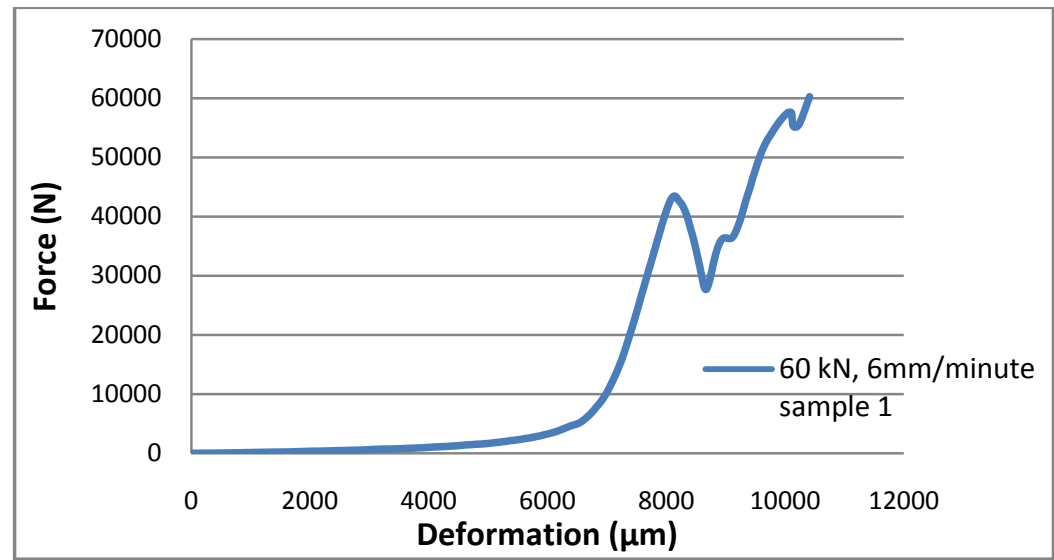

Gambar 8. Grafik hubungan Gaya dan Deformasi yang terjadi dengan beban tekan $60 \mathrm{kN}$ pada kecepatan $6 \mathrm{~mm} / \mathrm{menit}$

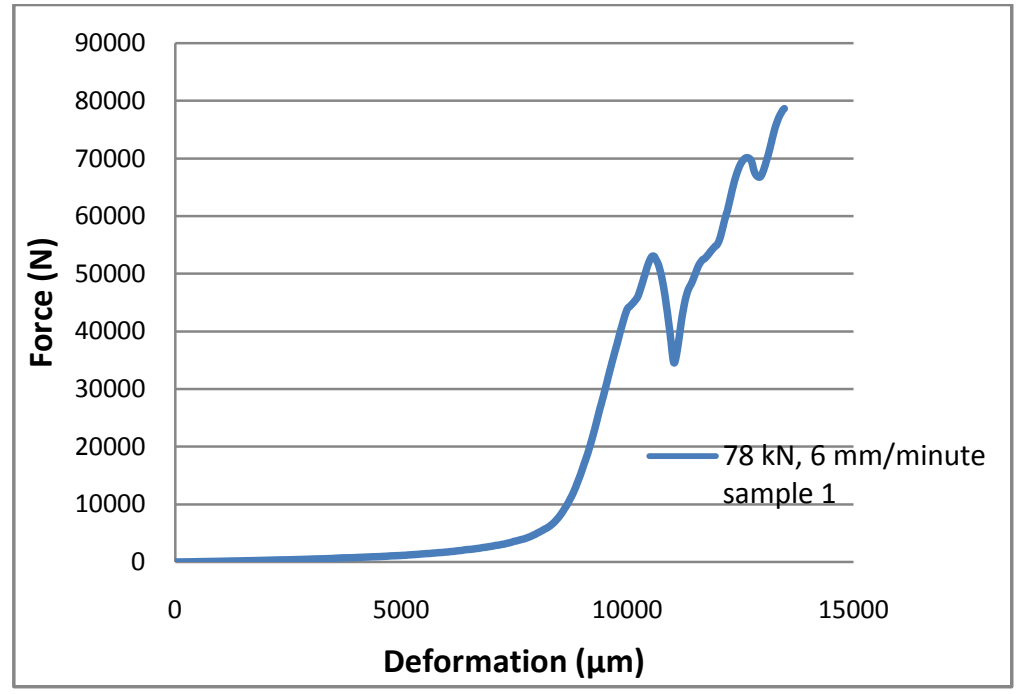

Gambar 9. Grafik hubungan Gaya dan Deformasi yang terjadi dengan beban tekan 78kN pada kecepatan $6 \mathrm{~mm} / \mathrm{menit}$

Tabel 1. Persentase kandungan minyak kelapa pada setiap variasi percobaan

\begin{tabular}{|c|c|c|c|c|c|c|c|c|}
\hline \multirow{2}{*}{$\begin{array}{l}\text { Force } \\
(\mathrm{kN})\end{array}$} & \multirow{2}{*}{$\begin{array}{c}\text { Speed } \\
\text { (mm/minute) }\end{array}$} & \multirow[b]{2}{*}{ Moisture } & \multicolumn{3}{|c|}{$\%$ Oil Content } & \multicolumn{3}{|c|}{$\%$ Total Oil Content } \\
\hline & & & Sample 1 & Sample 2 & Avarage & Sample 1 & Sample 2 & Avarage \\
\hline 24 & 6 & $41.13 \%$ & $18.76 \%$ & $23.12 \%$ & $20.94 \%$ & $11.00 \%$ & $13.60 \%$ & $12.30 \%$ \\
\hline 40 & 6 & $31.30 \%$ & $25.04 \%$ & $27.45 \%$ & $26.25 \%$ & $17.20 \%$ & $18.90 \%$ & $18.05 \%$ \\
\hline 60 & 6 & $41.13 \%$ & $27.49 \%$ & $32.75 \%$ & $30.12 \%$ & $16.18 \%$ & $19.30 \%$ & $17.74 \%$ \\
\hline 78 & 6 & $41.13 \%$ & $25.30 \%$ & & $25.30 \%$ & $14.90 \%$ & & $14.90 \%$ \\
\hline
\end{tabular}

\begin{tabular}{|c|c|c|c|c|c|c|c|c|}
\hline \multirow{2}{*}{$\begin{array}{c}\text { Force } \\
(\mathrm{kN})\end{array}$} & \multirow{2}{*}{$\begin{array}{c}\text { Speed } \\
\text { (mm/minute) }\end{array}$} & \multirow[b]{2}{*}{ Moisture } & \multicolumn{3}{|c|}{$\%$ Oil Content } & \multicolumn{3}{|c|}{$\%$ Total Oil Content } \\
\hline & & & sample 1 & Sample 2 & Avarage & sample 1 & Sample 2 & Avarage \\
\hline 40 & 6 & $31.30 \%$ & $25.04 \%$ & $27.45 \%$ & $26.25 \%$ & $17.20 \%$ & $18.90 \%$ & $18.05 \%$ \\
\hline 40 & 12 & $41.13 \%$ & $25.80 \%$ & $34.50 \%$ & $30.15 \%$ & $15.20 \%$ & $20.30 \%$ & $17.75 \%$ \\
\hline 40 & 18 & $41.13 \%$ & $26.80 \%$ & & $26.80 \%$ & $15.80 \%$ & & $15.80 \%$ \\
\hline
\end{tabular}




\begin{tabular}{|r|r|r|r|r|r|r|r|r|}
\hline \multirow{2}{*}{$\begin{array}{r}\text { Force } \\
(\mathrm{kN})\end{array}$} & \multirow{2}{*}{$\begin{array}{c}\text { Speed } \\
(\mathrm{mm} / \text { minute) }\end{array}$} & Moisture & sample 1 & Sample 2 & Avarage & sample 1 & Sample 2 & Avarage \\
\cline { 5 - 9 } & 12 & $41.13 \%$ & $25.80 \%$ & $34.50 \%$ & $30.15 \%$ & $15.20 \%$ & $20.30 \%$ & $17.75 \%$ \\
\hline 20 & 12 & $41.13 \%$ & $34.40 \%$ & & $34.40 \%$ & $20.30 \%$ & & $20.30 \%$ \\
\hline 30 & 12 & & &
\end{tabular}

\subsection{PEMBAHASAN}

Dengan menggunakan persamaan 1, 2 dan 3 maka diperoleh besarnya energi per unit volume yang dibutuhkan untuk kebutuhan desain tabung penekanan kopra seperti pada tabel 2 berikut.

Tabel 2. Besarnya energi deformasi dan energi per volume yang terjadi untuk setiap variasi percobaan

\begin{tabular}{|c|c|c|c|c|c|}
\hline $\begin{array}{l}\text { Force } \\
\text { (kN) }\end{array}$ & $\begin{array}{c}\text { Speed } \\
\text { (mm/minute) }\end{array}$ & $\begin{array}{l}\text { Average Oil } \\
\text { Content }\end{array}$ & $\begin{array}{l}\text { Deformasi } \\
\text { (mm) }\end{array}$ & $\begin{array}{c}\text { Energi } \\
\text { Deformasi }(\mathrm{J})\end{array}$ & $\begin{array}{c}\text { Energi/Volume } \\
\left(10^{6} \mathrm{~J} / \mathrm{m}^{3}\right)\end{array}$ \\
\hline 24 & 6 & $20.94 \%$ & 40.222 & 1172.27 & 7.15 \\
\hline 40 & 6 & $26.25 \%$ & 39.094 & 992.25 & 6.05 \\
\hline 60 & 6 & $30.12 \%$ & 43.33 & 6295.3 & 38.40 \\
\hline 78 & 6 & $25.30 \%$ & 43.631 & 9226.78 & 56.28 \\
\hline $\begin{array}{l}\text { Force } \\
(\mathrm{kN})\end{array}$ & $\begin{array}{c}\text { Speed } \\
\text { (mm/minute) }\end{array}$ & $\begin{array}{c}\text { Average Oil } \\
\text { Content }\end{array}$ & $\begin{array}{l}\text { Deformasi } \\
\text { (mm) }\end{array}$ & $\begin{array}{c}\text { Energi } \\
\text { Deformasi }(\mathrm{J})\end{array}$ & $\begin{array}{c}\text { Energi/Volume } \\
\left(10^{6} \mathrm{~J} / \mathrm{m}^{3}\right)\end{array}$ \\
\hline 40 & 6 & $26.25 \%$ & 39.094 & 992.25 & 6.05 \\
\hline 40 & 12 & $30.15 \%$ & 40.184 & 1623.18 & 9.90 \\
\hline 40 & 18 & $26.80 \%$ & 40.028 & 1907.43 & 11.63 \\
\hline $\begin{array}{l}\text { Force } \\
\text { (kN) }\end{array}$ & $\begin{array}{c}\text { Speed } \\
\text { (mm/minute) }\end{array}$ & $\begin{array}{l}\text { Average Oil } \\
\text { Content }\end{array}$ & $\begin{array}{l}\text { Deformasi } \\
\text { (mm) }\end{array}$ & $\begin{array}{c}\text { Energi } \\
\text { Deformasi }(J)\end{array}$ & $\begin{array}{c}\text { Energi/Volume } \\
\left(10^{6} \mathrm{~J} / \mathrm{m}^{3}\right)\end{array}$ \\
\hline 40 & 12 & $30.15 \%$ & 40.184 & 1623.18 & 9.90 \\
\hline 60 & 12 & $34.40 \%$ & 41.447 & 5770.41 & 35.20 \\
\hline
\end{tabular}

Dari tabel 2 terlihat bahwa kebutuhan energi deformasi dan energi per volume terendah adalah pada beban penekanan $40 \mathrm{kN}$ dengan laju penekanan $6 \mathrm{~mm} / \mathrm{menit}$ dengan rata-rata volume minyak kelapa yang dihasilkan sekitar 26\%. Dengan meningkatkan laju penekanan menjadi 12 $\mathrm{mm} /$ menit akan meningkatkan rata-rata volume minyak kelapa yang dihasilkan menjadi $30 \%$, namun menyebabkan peningkatan kebutuhan energi untuk deformasi hampir sebesar 2 kali lipat dan peningkatan kebutuhan energi per volume sebesar 50\%. Jika beban penekanan ditingkatkan lagi menjadi 60 dan $78 \mathrm{kN}$, akan menyebabkan peningkatan kebutuhan energi deformasi dan kebutuhan energi per volume yang jauh lebih besar tanpa peningkatan yang signifikan dari ratarata volume minyak kelapa yang dihasilkan.

\section{Kesimpulan}

Dari hasil penelitian ini dapat disimpulkan bahwa energi deformasi yang dibutuhkan untuk menghasilkan volume minyak kelapa yang optimal adalah sebesar 1000 joule dan rata-rata kebutuhan energi per volume adalah $6.10^{6} \mathrm{~J} / \mathrm{m}^{3}$ pada beban penekanan sebesar $40 \mathrm{kN}$ dan kecepatan penekanan $6 \mathrm{~mm} / \mathrm{menit}$. 


\section{Daftar Pustaka}

[1]. Suhardiyono, L., 1993, Tanaman Kelapa Budidaya dan Pemanfaatannya, Kanisius, Yogyakarta.

[2]. Nasruddin, Studi Kualitas Minyak Goreng Dari Kelapa (CocosnuciferaL.) Melalui Proses Sterilisasi dan Pengepresan PENGEPRESAN, Jurnal Dinamika Penelitian Industri Vol. 22 No. 1 Tahun 2011

[3].Thiruchelvam Thanaraj, Nimal D.A. Dharmasena, Upali Samarajeewa, Comparison of quality and yield of copra processed in CRI improved kiln drying and sun drying, Journal of Food Engineering 78 (2007) 1446-1451

[4].M. Mohanraj_, P. Chandrasekar, Drying of copra in a forced convection solar drier, Biosystem Engineering, 99 (2008 ) 604 - 607

[5]. [5]. Endang Sulistiowati, Efisiensi proses basah dan kering pada pembuatan minyak dan tepung kelapa dari buah kelapa segar, Simposium Nasional Teknologi Terapan (SNTT)3, 2015

[6]. Sujata Jena, H. Das, Modelling for vacuum drying characteristics of coconut presscake, Journal of Food Engineering 79 (2007)

[7].M. Divišová, D. Herák, A. Kabutey, V. Šleger, R. Sigalingging, T. Svatoňová, Deformation Curve Characteristics of Rapeseeds and Sunflower Seeds Under Compression Loading, Scientia agriculturae bohemica, 45, 2014 (3)

[8].A. Kabutey, M. Divišová, L. Sedláček, W.E. Boatri, T. Svatoňová, R. Sigalingging, Mechanical behaviour of oil palm Kernels (Elaeis Guineensis), Scientia agriculturae bohemica, 44, 2013 (1)

[9]. A. Kabutey, D. Herák, O. Dajbych, M. Divišová, W.E. Boatri, R. Sigalingging, Deformation energy of Jatropha curcas L. seeds under compression loading, Res. Agr. Eng. Vol. 60, 2014, No. 2 